\title{
Comunicação organizacional: árvore de derivação enunciativa com inspiração foucaultiana
}

\section{Organizational Communication: a Foucault-inspired tree of encunciative derivation}

\section{Comunicación Organizacional: árbol de derivación enunciativa con inspiración foucaultiana}

\section{Isaura Mourão}

- Doutora em Comunicação e Informação pela Universidade Federal do Rio Grande do Sul (UFRGS), com bolsa da Coordenação de Aperfeiçoamento de Pessoal de Nível Superior (Capes).

- $\quad$ Mestre em Comunicação e Interações Mediáticas pela Pontifícia Universidade Católica de Minas Gerais (PUC-Minas).

- $\quad$ Graduada em Jornalismo pela Universidade Federal de Minas Gerais (UFMG).

- $\quad$ Coordenadora do Grupo de Pesquisa em Comunicação Organizacional e Relações Públicas da Sociedade Brasileira de Estudos Interdisciplinares da Comunicação (Intercom).

- Integrante do Grupo de Pesquisa em Comunicação Organizacional, Cultura e Relações de Poder (GCCOP) da UFRGS

- $\quad$ Integrante do Grupo de Pesquisa Comunicação no Contexto Organizacional: aspectos teórico-conceituais (Dialorg) da PUC-Minas.

- $\quad$ E-mail: mouraoisaura@gmail.com.

\section{Rudimar Baldissera}

- Doutor em Comunicação Social pela Pontifícia Universidade Católica do Rio Grande do Sul (PUCRS).

- Mestre em Ciências da Comunicação/Semiótica pela Universidade do Vale do Rio dos Sinos (Unisinos).

- $\quad$ Professor do Departamento de Comunicação da Faculdade de Biblioteconomia e Comunicação da UFRGS.

- $\quad$ Professor do Programa de Pós-Graduação em Comunicação da UFRGS.

- $\quad$ Líder do Grupo de Pesquisa Comunicação Organizacional, Cultura e Relações de Poder (GCCOP), registrado no CNPq.

- Bolsista de produtividade do CNPq.

- $\quad$ E-mail: rudimar.baldissera@ufrgs.br 


\section{Resumo}

Este artigo apresenta procedimentos e achados de pesquisa que investigou a conformação do saber-prática discursiva da comunicação organizacional, realizada com inspiração na análise arqueológica foucaultiana. Para tanto, a pesquisa utilizou como corpus 669 artigos publicados no período de 2008 a 2018 em três revistas científicas e em anais de dois importantes congressos da área, evidenciando a prevalência da matriz gestionária na constituição do saber-prática discursiva da comunicação organizacional.

\section{PALAVRAS-CHAVE: COMUNICAÇÃO ORGANIZACIONAL・SABER-PRÁTICA DISCURSIVA•ANÁLISE ARQUEOLÓGICA・VERDADES CONCEITUAIS - METODOLOGIA.}

\section{Abstract}

This article presents the methodological procedures and findings of a research on the discursive knowledge-practice conformation in organizational communication, inspired on Foucault's archaeological analysis. This research was conducted with a corpus of 669 articles published in three scientific journals from 2008 to 2018 and proceedings of two important congresses in the field. The results evince the prevalence of the management matrix within the constitution of the discursive knowledge-practice of Organizational Communication.

KEYWORDS: ORGANIZATIONAL COMMUNICATION • DISCURSIVE KNOWLEDGE-PRACTICE • ARCHAEOLOGICAL ANALYSIS •CONCEPTUAL TRUTHS -METHODOLOGY.

\section{Resumen}

En este artículo presentamos los procedimientos y los hallazgos de una investigación que indagó la conformación del conocimiento-práctica discursiva de la comunicación organizacional teniendo como base el análisis arqueológico foucaultiano. Para ello, utilizamos el corpus de 669 artículos publicados, en el periodo de 2008 a 2018, en tres revistas científicas y en actas de dos importantes congresos del área, para destacar la prevalencia de la matriz de gestión en la constitución del conocimiento-práctica discursiva de la comunicación organizacional. 


\section{INTRODUÇÃO}

$\mathrm{E}$

m nossos estudos, compreender a comunicação organizacional como saber-prática discursiva significa imprimir um outro olhar para o encadeamento conceitual da área, inspirado pela perspectiva foucaultiana e considerando, portanto, as relações poder-saber-verdade em sua conformação. Afinal, segundo Foucault (2012a), é por meio dessas articulações que uma prática discursiva se constitui e, nesse sentido, ela não deve ser reduzida a um conjunto de enunciados ${ }^{1}$, a um discurso ou ao modo de fabricação de um discurso: é mais que isso, uma vez que se conforma a partir de regras pactuadas pelas relações entre enunciados discursivos e não discursivos que definem as condições de exercício da função enunciativa e, consequentemente, fazem emergir as formações discursivas².

Em decorrência disso, uma prática discursiva só ganha existência na relação exterior dos enunciados e das formações discursivas, em articulações e enfrentamentos que resultam em sentidos apropriados como verdades conceituais conformando um saber. Nessa visada, inspirar-nos na lógica foucaultiana para estudar a comunicação organizacional implica uma análise singular desse sistema de pensamento, regido por princípios de exclusão e de escolha que se dão nas diferentes relações e fazem emergir certos enunciados em detrimento de outros, reiterando verdades conceituais. Com base nesses pressupostos, no desenvolvimento da tese de doutoramento ${ }^{3}$ que subsidia as reflexões deste artigo, buscou-se demonstrar as relações de força e a função enunciativa exercida por enunciados discursivos e não discursivos que levaram ao encadeamento das formações discursivas/construtos ${ }^{4}$, fazendo emergir o saber-prática discursiva da comunicação organizacional.

Nessa perspectiva, o artigo começa discorrendo sobre os principais conceitos foucaultianos que inspiraram e fundamentaram a referida pesquisa. Na sequência, enquanto apresenta os procedimentos adotados, aponta os achados nas diferentes etapas do processo investigativo. Num primeiro momento, foram identificados autores em posições subjetivas, nas quais se encontram por serem reconhecidos como au torizados a falar do objeto num determinado campo científico, no caso, da comunicação organizacional. Na fase seguinte, foram esquadrinhadas as formações discursivas construídas por esses autores, que são apropriadas e reverberadas por outros. Por fim, a pesquisa investigou como essas formações discursivas foram apropriadas e, por vezes, ressignificadas por outros no processo de apropriação. Na construção desse encadeamento conceitual, evidenciam-se as relações de força presentes nas articulações entre enunciados/formações discursivas/função enunciativa, num jogo permanente de poder-saber-verdade que faz emergir, por fim, os construtos situados na copa da árvore de derivação enunciativa da comunicação organizacional.

\section{PERSPECTIVA FOUCAULTIANA: PONTO DE PARTIDA}

A árvore de derivação enunciativa é a metáfora utilizada por Foucault (2012a) para descrever sua proposta de análise arqueológica do discurso. Caracterizada "pelo recorte de um campo de projetos, pela definição de uma perspectiva legítima

\footnotetext{
1 Para Foucault (2012a), os enunciados precisam ser compreendidos em sua função enunciativa, ou seja, conforme o sentido com que são apropriados/significados resultando em formações discursivas. As formações discursivas são então definidas a partir da descrição de certo número de enunciados em semelhante sistema de dispersão, numa regularidade e numa ordem determinadas "entre os objetos, os tipos de enunciação, os conceitos, as escolhas temáticas" (p.47), submetidos a regras de formação/função enunciativa.

20 que Foucault (2012a) descreve "sob o nome de formação discursiva constitui, em sentido estrito, grupos de enunciados, isto é, conjuntos de performances verbais [...] ligadas no nível dos enunciados" (p.141, grifo do autor). Nessa perspectiva, as descrições da função enunciativa e das formações discursivas apresentam-se como correlatas e possibilitam delimitar a noção de prática discursiva.

3 A tese A construção do saber-prática discursiva da comunicação organizacional no Brasil foi defendida por Isaura Mourão Generoso, em março de 2019, na Universidade Federal do Rio Grande do Sul, e teve como orientador o Prof. Dr. Rudimar Baldissera.

4 No presente artigo, formações discursivas e construtos são utilizados como sinônimos, uma vez que apresentam as noções conceituais acerca da comunicação organizacional.
} 
para o sujeito de conhecimento, pela fixação de normas para a elaboração de conceitos e teorias" (Foucault, 1997, p.11), essa análise proporciona um olhar diferenciado para a investigação de uma prática discursiva. A ênfase está nas relações entre enunciados discursivos e não discursivos, na função enunciativa por eles exercida nessas relações e na interdependência das noções poder, saber, verdade.

Com o intuito de proporcionar mais nitidez ao seu pensamento, o autor serve-se da relação entre os signos e a língua, ressaltando que os signos que compõem a língua só adquirem sentido ao exercerem uma função enunciativa, quando são configuradas as relações de poder na construção do sentido. Emergem daí "o conjunto de procedimentos que permitem a cada instante e a cada um pronunciar enunciados que serão considerados verdadeiros" (Foucault, 2012b, p. 227) ou, em outros termos, os construtos assumidos com efeito de verdade. Nessa visada, as formações discursivas são resultado de um movimento complexo, regido por enunciados reitores que se encontram na raiz da árvore de derivação enunciativa,

influenciando a formação de ramificações e dos enunciados articulados em sua copa. Tais enunciados - que podem ou não ser discursivos cumprem, por meio de suas relações, uma função enunciativa produzindo "verdades" reverberadas em formações discursivas articuladas a partir de regras de inclusão e de exclusão, conformando uma "prática discursiva" que, por sua vez, faz emergir um "saber". (Mourão, 2019, p. 17)

Essas articulações, marcadas pela tensão entre saber e poder sobre algo ou alguma coisa, geram normas que sugerem "um jogo de prescrições que determinam exclusões e escolhas" (Foucault, 1997, p.11) na conformação discursiva. Nesse jogo, controlado por regras e condições de exercício da função enunciativa, são também definidas as posições subjetivas ${ }^{5}$ que um indivíduo pode ocupar para se tornar sujeito do enunciado. No entanto, mais do que identificar essas posições ou a autoria do discurso, importa compreender como algo ou alguma coisa pode ser dita - e assumida como verdade - por determinados sujeitos em condições específicas (Foucault, 1997, 2012a, 2012b, 2012c). Trata-se de uma forma complexa de compreensão dos saberes e de sua conformação, uma vez que propicia a investigação do encadeamento de uma prática discursiva para além da interpretação ou da formalização de um discurso.

Assim, ao analisar um discurso a partir de Foucault (2012b), devemos considerar a interdependência e a inter-relação entre verdade, saber e poder. Nesse caso, poder não está associado a algo negativo ou repressor e não se reduz a uma força que diz não, mas como "força produtiva" que "permeia, produz coisas, induz ao prazer, forma saber, produz discurso" (Foucault, 2012c, p.45). Por esse ângulo, saber e poder são coexistentes e constituídos por relações mútuas, pois "todo ponto de exercício do poder é, ao mesmo tempo, um lugar de formação de saber" (Foucault, 2012c, p.28). Nessa visada, saber é definido como aquilo de que se pode falar em uma prática discursiva e abarca tanto o conhecimento científico quanto a compreensão, a experiência vivida e as práticas. A experiência em si, desde que gere enunciados considerados verdadeiros e produza verdade, já se configura como um saber.

Partindo dessa perspectiva, a análise de um saber-prática discursiva deve considerar relações entre: 1) o domínio dos objetos, compreendido como aquilo de que se pode falar em uma determinada prática discursiva; 2) as posições subjetivas - sujeitos autorizados a falar dos objetos em um determinado espaço/campo por serem reconhecidos por outros sujeitos nesse lugar; 3) o campo dos enunciados no qual os conceitos se movimentam; e 4) as possibilidades de utilização e de apropriação das formações discursivas e, consequentemente, dos discursos. A análise dessas relações conduz às verdades enunciativas que podem ser vistas na copa de uma árvore de derivação enunciativa, em que os enunciados de um saber-prática discursiva aparecem consolidados e da forma como são reverberados.

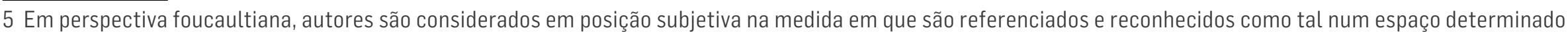

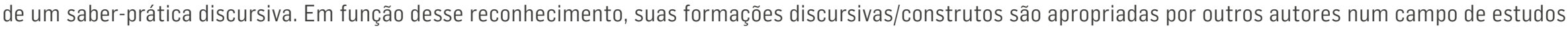
específico.
} 
Dessa maneira, alcançamos conceitualmente o que denominamos saber-prática discursiva a partir da lógica foucaultiana. Em outros termos, saber é o que emerge das relações de força e de poder em decorrência das articulações discursivas e não discursivas. Dentre as não discursivas, estão fatores estruturais - históricos, societários, políticos e econômicos, como a organização da sociedade segundo o sistema capitalista - que conferem uma determinada visão de mundo e um sistema de crenças, em articulação constante, oferecendo instrumentos e procedimentos assumidos como verdades.

\section{DA RAIZ À COPA: PERCURSO ADOTADO E ACHADOS}

A partir das pistas oferecidas por Foucault (2012a) para a análise arqueológica do discurso, a pesquisa mencionada desenvolveu um procedimento de pesquisa capaz de interpelar a comunicação organizacional como saber-prática discursiva, organizado em três etapas inter-relacionadas: 1) a identificação de autores/pesquisadores em posições subjetivas cujas formações discursivas/construtos são apropriadas por outros, 2) a apreensão dos construtos desses autores acerca da comunicação organizacional, sempre em relações com outros enunciados; e 3) a apropriação desses construtos por outros autores que fazem emergir as verdades em comunicação organizacional (Mourão, 2019). Tais procedimentos dão a ver as relações de força e de poder entre enunciados/formações discursivas na conformação da árvore de derivação enunciativa.

Na primeira etapa desse percurso investigativo, foram identificados os autores/pesquisadores ${ }^{6}$ em posições subjetivas por meio de uma análise que adotou parâmetros quantitativos, pois é a frequência com que seus construtos são acionados e apropriados por outros, no espaço científico, que os coloca nesse lugar. Como espaço científico de reverberação desse conhecimento, foi delimitado o Congresso Nacional da Associação Brasileira de Pesquisadores de Comunicação Organizacional e de Relações Públicas (Abrapcorp), por ser o único congresso específico da área no Brasil, que reúne pesquisadores em diferentes momentos da carreira, além de professores, estudantes e profissionais. Assim, foram analisados $631^{7}$ artigos apresentados e publicados nos anais de 11 edições do Congresso da Abrapcorp, de 2008 a 2018, período definido pela pesquisa que subsidia o estudo. Para elencar as posições subjetivas, foram definidos os seguintes critérios: autores que tivessem sido 1) citados em pelo menos 10 das 11 edições do congresso, 2) referenciados pelo menos 110 vezes no período; e 3) usados como referência em, no mínimo, 22 artigos apresentados e publicados nos anais do congresso no período. Tais critérios levaram à identificação de nove autores nessa posição (Tabela 1).

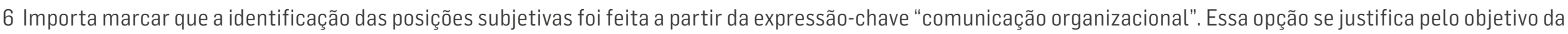

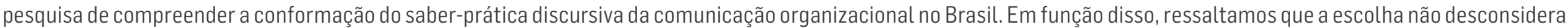

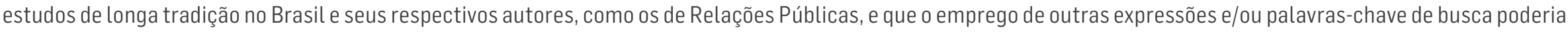

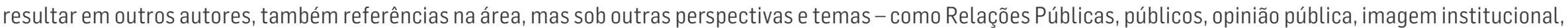

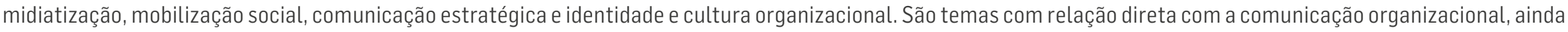

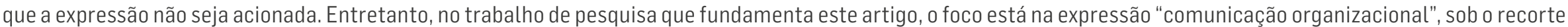
da área da comunicação, entre 2008 e 2018.

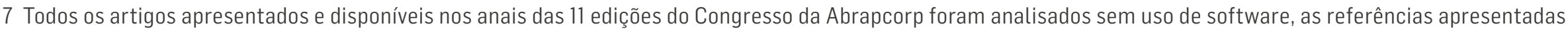

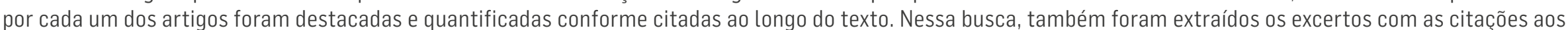

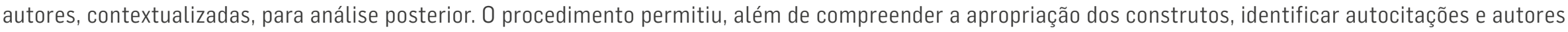
diferentes com mesmo sobrenome.
} 
Tabela 1: Autores em comunicação organizacional mais citados nos artigos disponíveis nos Anais do Congresso da Abrapcorp, de 2008 a 2018

\begin{tabular}{|c|c|c|c|c|c|c|c|c|c|c|c|c|}
\hline \multirow{2}{*}{$\begin{array}{l}\text { Pesquisadores Comunicação } \\
\text { Organizacional em } \\
\text { "posições subjetivas" }\end{array}$} & \multicolumn{12}{|c|}{ Congressos Abrapcorp realizados no período entre 2008 e 2018} \\
\hline & 2008 & 2009 & 2010 & 2011 & 2012 & 2013 & 2014 & 2015 & 2016 & 2017 & 2018 & $\begin{array}{l}\text { Total de artigos nos } \\
\text { quais foram citados }\end{array}$ \\
\hline Margarida Maria Krohling KUNSCH & 15 & 20 & 12 & 13 & 8 & 16 & 22 & 16 & 18 & 13 & 18 & 171 \\
\hline Rudimar BALDISSERA & 3 & 4 & 8 & 5 & 6 & 9 & 15 & 12 & 14 & 16 & 9 & 101 \\
\hline Ivone de Lourdes OLIVEIRA & 3 & 2 & 10 & 4 & 5 & 8 & 11 & 8 & 8 & 10 & 9 & 78 \\
\hline Marlene MARCHIORI & 2 & 3 & 3 & 6 & 5 & 5 & 13 & 4 & 6 & 3 & 6 & 56 \\
\hline Wilson da Costa BUENO & 6 & 11 & 4 & 5 & 1 & 4 & 3 & 5 & 3 & 6 & 5 & 53 \\
\hline Maria Aparecida FERRARI & 2 & 1 & 3 & 1 & 2 & 4 & 10 & 9 & 5 & 5 & 9 & 51 \\
\hline Cleusa Maria Andrade SCROFERNEKER & 2 & 4 & 10 & 3 & 2 & 7 & 4 & 3 & 4 & 1 & 4 & 44 \\
\hline Paulo Roberto NASSAR de Oliveira & 4 & 2 & 5 & 0 & 3 & 1 & 8 & 6 & 6 & 4 & 4 & 43 \\
\hline João José Azevedo CURVELLO & 0 & 4 & 3 & 3 & 1 & 5 & 4 & 3 & 2 & 2 & 4 & 31 \\
\hline
\end{tabular}

Fonte: Mourão (2019, p. 68).

Na perspectiva da análise arqueológica do discurso, identificar as posições subjetivas cujos construtos são apropriados por outros autores, pesquisadores, professores, estudantes e profissionais da área tornam-se fundamentais para compreender as relações exteriores entre os enunciados e as formações discursivas. Dessas relações, que também são de poder, emergem as formações discursivas que assumem efeito de verdade e conformam o saber-prática discursiva da comunicação organizacional. Por meio de seus construtos, as posições subjetivas proporcionam um lugar determinado às organizações de conceitos, aos reagrupamentos de objetos e a certos tipos de enunciação, temas e teorias.

Segue-se, então, em direção à segunda etapa do percurso investigativo da referida pesquisa: a compreensão dos construtos postulados pelos autores identificados sobre comunicação organizacional. Para isso, utilizou-se como espaço científico no qual os conceitos se movimentam, no mesmo período de 2008 a 2018, três revistas científicas e um congresso: a Revista Brasileira de Comunicação Organizacional e Relações Públicas (Organicom); a Revista Brasileira de Ciências da Comunicação (Intercom-RBCC); a Revista E-Compós e os congressos da Associação Nacional dos Programas de Pós-Graduação em Comunicação (Compós) ${ }^{8}$.

Nessa etapa do percurso investigativo, foram identificados e analisados 38 artigos apresentados e/ou publicados pelos nove autores/ pesquisadores com o objetivo de apreender e esquadrinhar os construtos sobre comunicação organizacional postulados por eles. Além de se chegar aos construtos/formações discursivas por eles assumidas e/ou construídas, constatou-se a filiação teórica de cada um dos autores em posições subjetivas e as respectivas áreas de origem, que podem ser consideradas as raízes de seus postulados.

Alcançamos, assim, o domínio dos objetos (Foucault, 2012a), ou seja, as formações discursivas/construtos desenvolvidos pelos autores em posições subjetivas, as principais referências utilizadas que remetem a fundamentos e às regras de formação que regem e orientam seus construtos. Importa destacar que os achados não se prendem às especificidades de cada um dos nove pesquisadores, mas demonstram a função enunciativa que exercem nas relações e articulações entre enunciados discursivos e não discursivos. 
Dessa forma, apontaram a emergência de formações discursivas cujos enunciados reitores são oriundos dos Estudos Organizacionais e de outras formações, cujas raízes estão nos campos da comunicação, da filosofia, da psicologia e da sociologia. Esses construtos são apresentados na Figura 1, numa primeira representação da árvore de derivação enunciativa da comunicação organizacional. Fundamentados em bases teóricas dos diferentes campos são encadeados em relações de força e em articulação com formações não discursivas enraizadas nos modelos, práticas e comportamentos regrados pelo sistema capitalista.

Figura 1: Construtos da comunicação organizacional em relações de força

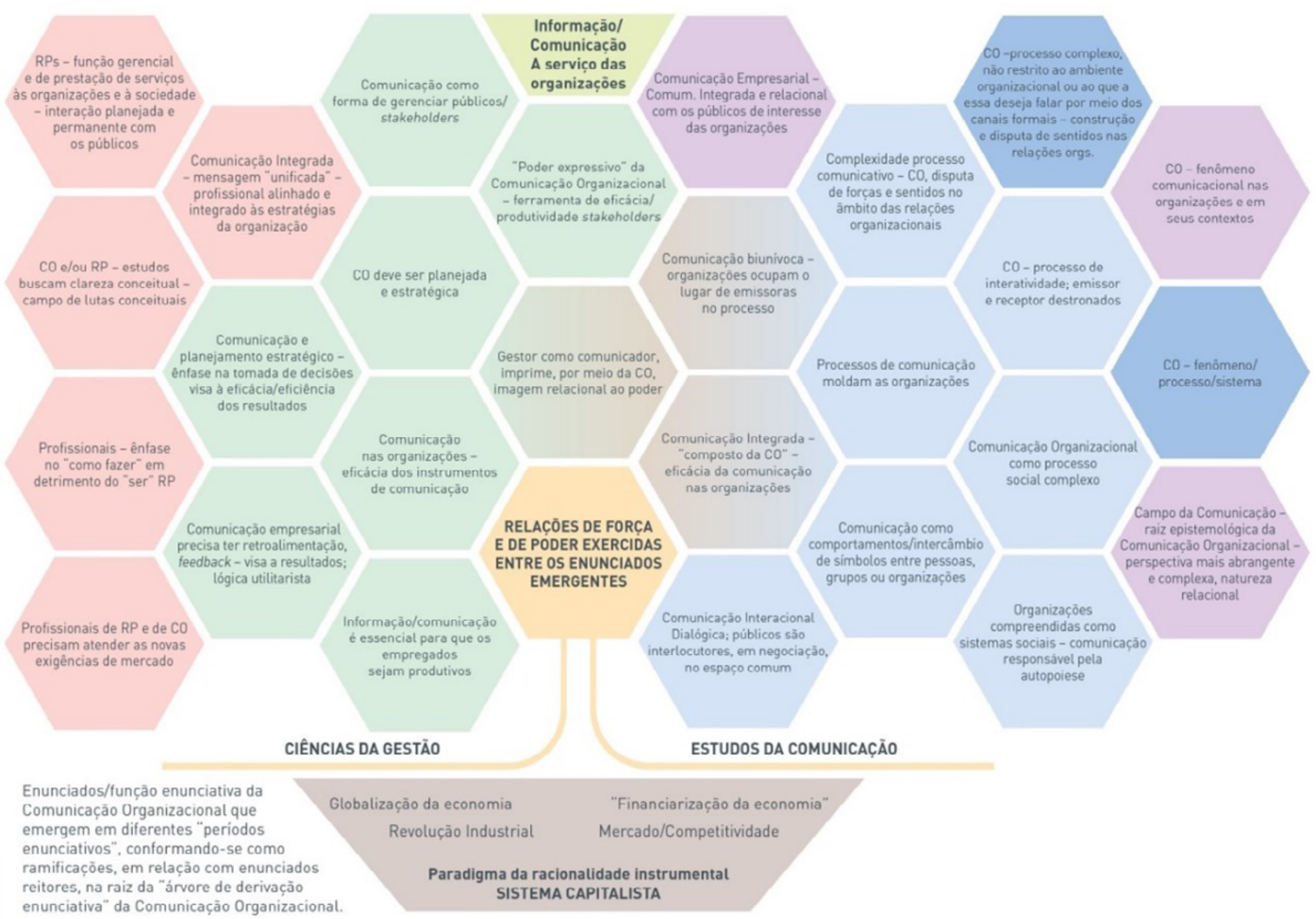

Fonte: Mourão (2019, p. 115).

Na representação dessa árvore de derivação enunciativa, o sistema capitalista e o paradigma da racionalidade instrumental encontram-se na base e são compreendidos como enunciados reitores não discursivos ${ }^{9}$. Deles emergem outros enunciados discursivos e não discursivos, como a Revolução Industrial, seguida de modelos gestionários criados com vistas a buscar soluções para enfrentar a concorrência e a competitividade de mercado, a globalização e a financiarização da economia, sobretudo na sociedade ocidental. Nesse encadeamento, as Ciências da Gestão passam a pautar mais efetivamente comportamentos organizacionais e individuais, conforme alerta Gaulejac (2007). Todos esses enunciados, discursivos e não discursivos, se configuram como enfrentamentos e relações de força e de poder que também impactam e influenciam a construção discursiva

\footnotetext{
9 Importa ressaltar que, em perspectiva foucaultiana, o enunciado não se restringe à frase, à proposição ou aos atos de fala, ainda que também possam se configurar como enunciados, dependendo das relações e articulações que estabelecem com outras frases e/ou proposições. Assim, o enunciado é da ordem da raridade, pois está sempre em relação ao que enuncia, relação que pode não ser idêntica por não utilizar as mesmas regras de formação, mas que funciona como um elemento que possibilita interrogar as regras de um discurso que se vai compondo no seu feixe de relações e articulações. Nesse sentido, os enunciados tanto podem ser discursivos como não discursivos. Como exemplos podemos pensar no sistema capitalista (algo mais abrangente) e no sistema de gestão (mais específico) configurando-se como enunciados não discursivos, pois exercem função enunciativa na conformação de um saber-prática discursiva como o da comunicação organizacional.
} 
dos estudos e conceitos da comunicação organizacional, exercendo funções enunciativas e materializando-se nas formações discursivas construídas pelos autores/pesquisadores em posições subjetivas.

Percebemos ainda, ao elucidar essa árvore de derivação enunciativa, os campos das ciências da gestão e da comunicação fundamentando a conformação conceitual da área. Ao afiliarem-se mais fortemente a um desses campos, as posições subjetivas adotam regras de inserção/exclusão de determinada função enunciativa na derivação de enunciados discursivos da comunicação organizacional. Com o intuito de conferir mais visibilidade às vinculações teóricas desses autores/pesquisadores que geram, consequentemente, formações discursivas mais próximas ou mais distantes, os construtos que deles emergem foram organizados em cores diferentes na árvore de derivação enunciativa.

Dessa forma, os seis construtos situados na parte inferior da copa da árvore podem ser considerados os enunciados reitores discursivos da comunicação organizacional e têm forte vinculação com os enunciados reitores não discursivos mencionados e apresentados na base da árvore. Os situados à esquerda, na cor verde, encontram-se mais vinculados às ciências da gestão e ao paradigma utilitário e informacional, já os situados à direita, na cor azul, ao campo da comunicação e aos paradigmas sistêmico e da complexidade.

Das relações com enunciados reitores e suas respectivas funções enunciativas, emergem as formações discursivas que trazem em si escolhas teóricas estratégicas e verdades conceituais que foram organizadas em três grupos: o primeiro, caracterizado pela cor rosa, tem autores mais fortemente vinculados aos estudos organizacionais e aos modelos gestionários, imprimindo visada mais utilitária e estratégica a seus construtos, com ênfase nas noções de controle, eficiência e eficácia da comunicação no âmbito das organizações; o segundo grupo, marcado em roxo, abarca conceitos que adquirem visada de maior complexidade e abrangência, partindo do princípio de que a comunicação é de natureza relacional, mas que também deve ser considerada de forma integrada e gerida com vistas aos objetivos e propósitos organizacionais; e o terceiro grupo, em azul mais escuro, apresenta construtos desvinculados da perspectiva gestionária da comunicação organizacional, construindo formações discursivas fundamentadas pelos estudos da comunicação, da filosofia e da psicologia, considerando-a como processo sistêmico e complexo. No Quadro 1, Mourão (2019, p.127) buscou indicar relações de força e aproximações entre enunciados/função enunciativa que emergem do encadeamento da noção de comunicação organizacional e os que decorrem de postulados dos autores em posições subjetivas, organizadas em grupos, e em relações de sobreposição e/ou de complementaridade. 


\section{Quadro 1: Formações discursivas/construtos que emergem dos autores/pesquisadores em posições subjetivas}

\section{Enunciados que emergem do encadeamento da noção de CO}

\section{Formações discursivas que emergem dos enunciados de pesquisadores em "posições subjetivas"}

Comunicação e planejamento estratégico - ênfase na tomada de decisões visa à eficácia/eficiência dos resultados.

"Poder expressivo" da comunicação organizacional -

ferramenta de eficácia/produtividade stakeholders.

Comunicação como forma de gerenciar públicos/stakeholders. Informação/comunicação é essencial para que os empregados sejam produtivos.

Gestor como comunicador, imprime, por meio da CO, imagem relacional ao poder.

Comunicação empresarial precisa ter retroalimentação, feedback - visa a resultados; lógica utilitarista.

Comunicação nas organizações - eficácia dos instrumentos de comunicação.

CO deve ser planejada e estratégica.

Profissionais de RP e de CO precisam atender às novas exigências de mercado.

Profissionais - ênfase no "como fazer" em detrimento do "ser" RP.

Comunicação integrada - mensagem "unificada" - profissional alinhado e integrado às estratégias da organização.

Comunicação interacional dialógica; públicos são interlocutores, em negociação, no espaço comum.

Comunicação organizacional como processo social.

Processos de comunicação moldam as organizações.

Comunicação organizacional - fenômeno comunicacional nas organizações e em seus contextos.

Campo da comunicação - raiz epistemológica da comunicação organizacional - perspectiva mais abrangente e complexa, natureza relacional.

Comunicação integrada - "composto da comunicação organizacional" - eficácia da comunicação nas organizações.

Comunicação como comportamentos/intercâmbio de símbolos entre pessoas, grupos ou organizações.
1) a comunicação integrada deve ter um "discurso unificado" e ser planejada por uma gestão centralizada, visando ao controle e estratégias, à obtenção de resultados e redução de ruídos. Para se gerenciar e controlar a comunicação, é necessário gerenciar a escuta, os ativos intangíveis e desenvolver estratégias comunicativas respaldadas na interação e no diálogo com os públicos.

2) a comunicação organizacional como atividade de influência permanente sobre os públicos de interesse das organizações deve estar no "cerne" dos negócios, desenvolvida no "board" e não só pelos comunicadores, já que se integra aos objetivos e estratégias estabelecidos no planejamento da organização e da gestão dos negócios. É processo no qual significados são criados, trocados e/ou compartilhados pelas "partes envolvidas" e cuja gestão, decorrente do modelo de gestão da organização, deve resultar em êxito para os negócios.

3) a comunicação, nas organizações, configura-se como processo em movimento contínuo nos ambientes organizacionais, indo além da visão informacional, e é "primordial para sustentar" o desenvolvimento organizacional.

4) a comunicação organizacional é aquela que valoriza e incorpora a opinião da sociedade e dos públicos com os quais a organização se relaciona e, na atualidade, ela deve "adotar como alvo" relações mais abertas, com múltiplas vozes, e compreender os públicos-alvo como coautores da legitimidade organizacional.

5) a comunicação organizacional é de natureza relacional e, portanto, o "ato comunicativo" configura-se como "espaço de negociação" no qual os públicos, incluindo as organizações, são considerados atores sociais e interlocutores. Assim, configurase como fenômeno interativo e multifacetado em contraponto à gestão como controle, marca do contexto organizacional.

6) a comunicação organizacional deve ser analisada em três dimensões: a humana, a instrumental e a estratégica, sendo essas duas mais técnicas e funcionais, e predominantes na comunicação nas e das organizações. Já a humana nasce como necessidade de se atentar para a humanização das organizações, permitindo, por meio da comunicação, a abertura de canais de diálogo e proporcionando maior valorização das pessoas.

7) a comunicação organizacional configura-se como um processo complexo que revela, nessa compreensão, a exaustão de um paradigma simplificador, mas convivendo com este sem negá-lo ou excluí-lo. 
Quadro 1: Continuação

Enunciados que emergem do encadeamento da noção de CO

Organizações compreendidas como sistemas sociais

- comunicação responsável pela autopoiese.

Comunicação organizacional - processo de interatividade - emissor e receptor destronados.

Comunicação organizacional - fenômeno/processo/sistema.

Complexidade processo comunicativo - Comunicação organizacional, disputa de forças e sentidos no âmbito das relações organizacionais.

Comunicação organizacional - processo complexo, não restrito ao ambiente organizacional ou ao que a essa deseja falar por meio dos canais formais.
Formações discursivas que emergem dos enunciados de pesquisadores em "posições subjetivas"

8) a comunicação organizacional deve ser compreendida a partir da abordagem sistêmico-comunicacional de Luhmann, que enfatiza a relação de diferenciação entre sistema organizacional e ambiente, quebrando a análise do todo e da parte e buscando novas formas de se apreender a CO, com ênfase ao enfoque interacional, circular e sistêmico, que só faz sentido quando seus componentes transmissão, mensagem e recepção - são considerados em relação. A CO é um processo, visto que se trata de um fenômeno que apresenta contínua mudança no tempo, no qual ocorre a autopoiese entre sistema e ambiente, em fluxo e em transformações constantes

9) a comunicação organizacional deve ser compreendida como processo que não está restrito à gestão ou ao planejamento da comunicação na e/ou da organização. Esse processo, no qual ocorre a construção e a disputa de sentidos no âmbito das relações organizacionais, deve ser apreendido em três dimensões tensionadas e interdependentes: a "organização comunicada", que considera a fala autorizada e normalmente planejada pela organização; a "organização comunicante", que compreende a fala autorizada e demais processos comunicacionais que se atualizam em relações diretas com a organização; e a "organização falada", dimensão que considera toda comunicação que não tem relação direta com a organização, mas que a ela se refere.

Fonte: Mourão (2019, p. 127).

Apresentados os construtos na forma de uma árvore de derivação enunciativa, como na Figura 1, torna-se possível avistar o domínio dos objetos e o campo dos enunciados no qual os conceitos se movimentam. Ficam expostas, ainda, as funções enunciativas dos enunciados discursivos e não discursivos em contínuas relações de forças que nos ajudam a compreender a complexidade do nosso campo de atuação.

No entanto, a apreensão da árvore de derivação enunciativa da comunicação organizacional não se esgota nesses achados, do domínio dos objetos. Como explicitamos anteriormente, o saber-prática discursiva conforma-se, de fato, pela apropriação e consequente reverberação dos enunciados/formações discursivas assumidas como construtos verdadeiros. Para tanto, foram necessárias investigações que integraram a terceira etapa dos procedimentos da pesquisa. Nessa fase, voltou-se aos 631 artigos publicados nas 11 edições do congresso da Abrapcorp de 2008 a 2018 para investigar como as formações discursivas/construtos esquadrinhados na etapa anterior foram apropriados e reverberados por outros autores, pesquisadores, professores, estudantes e profissionais da área.

Como o objetivo foi observar a apropriação dos conceitos das posições subjetivas pelos demais autores, foi necessário excluir 50 dos 631 artigos que eram de autoria dos ou escritos em coautoria com os próprios sujeitos em posições subjetivas. Assim, ficaram 581 artigos, nos quais se buscou observar como os construtos dos nove autores foram apropriados por outros autores. Nesse universo de 581 artigos, 342 - 0 equivalente a quase $60 \%$ do total - usaram formações discursivas apresentadas na Figura 1, postuladas por um ou mais autores em posições subjetivas. Voltando a estes 342 artigos, identificou-se a apropriação e como as formações discursivas foram reverberadas com efeitos de verdade.

No processo de análise, constatou-se que grande parte das formações discursivas, sobretudo as mais vinculadas à comunicação, à filosofia, à psicologia e à sociologia, que se distanciaram de enunciados reitores das ciências da gestão, voltaram, na 
apropriação por outros autores, a ser regradas por enunciados/função enunciativa que têm como raiz a busca por eficiência e por resultados organizacionais. Dessa forma, passaram a adquirir sentidos que voltam a enraizá-las ao viés econômico e aos modelos de gestão. Infere-se, com isso, que as relações de força oriundas dos estudos organizacionais fazem prevalecer sentidos marcados pelo viés econômico da construção conceitual "em detrimento daqueles que marcavam suas diferenças, enfatizando não o processo ou o fenômeno comunicacional no âmbito das organizações, mas temas, produtos e/ou modos de 'fazer' comunicação organizacional" (Mourão, 2019, p. 156). Essa apropriação e ressignificação são apresentadas na Figura 2.

Figura 2: Árvore de derivação enunciativa da comunicação organizacional

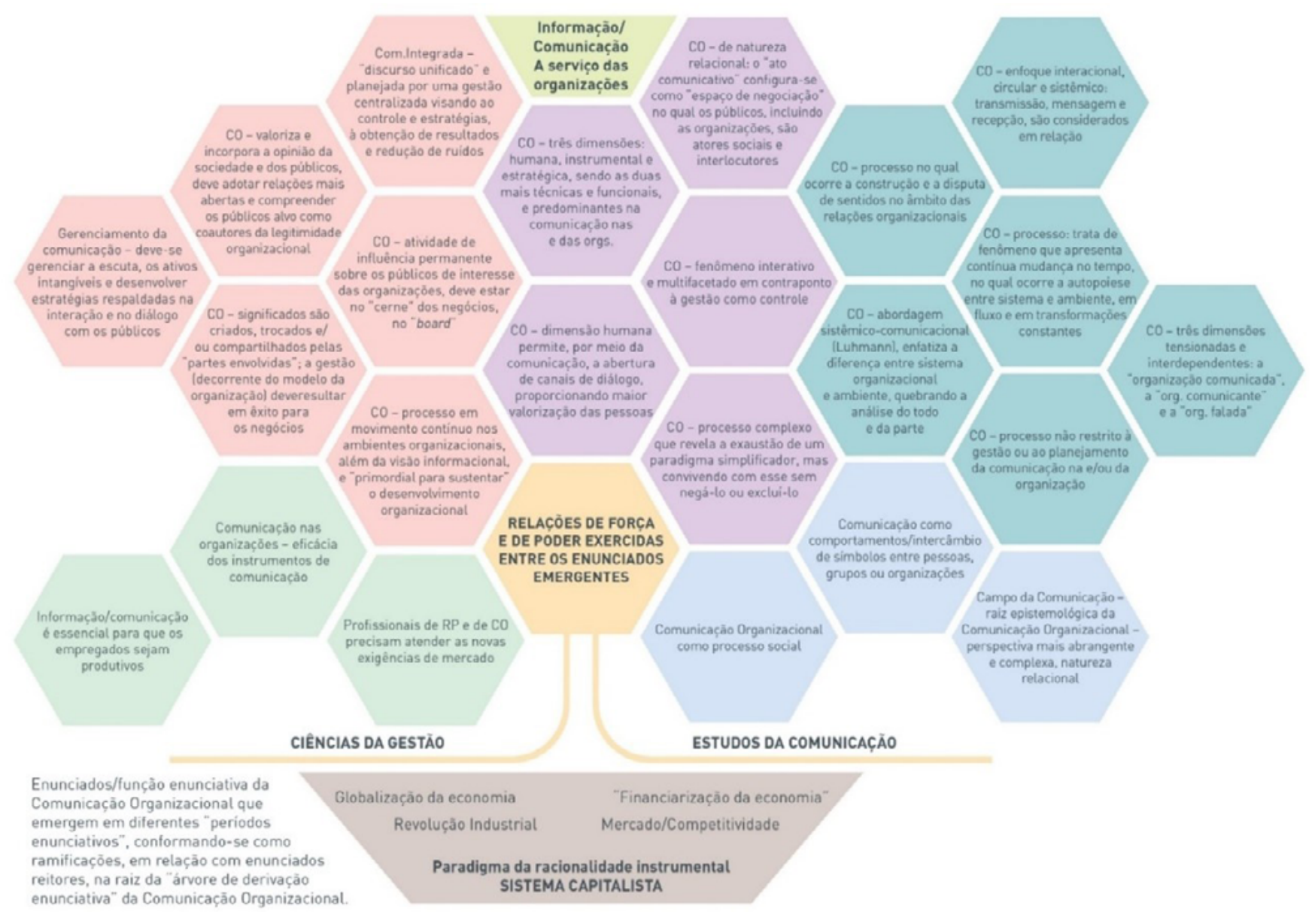

Fonte: Mourão (2019, p. 153).

Na Figura 2, formações discursivas cuja tendência seria a constituição de um saber-prática discursiva da comunicação organizacional fundamentado por uma perspectiva comunicacional e por caracterizar o processo como prática social complexa, configurando-o como uma reescrita, ao serem apropriadas por outros autores permanecem obedecendo a regras que posicionam a comunicação organizacional como conjunto de coisas utilitárias e a favor do engajamento de empregados, dos demais públicos de relacionamento e da sociedade aos objetivos organizacionais. Em outros termos, essas formações são apropriadas e ressignificadas no sentido de serem aplicadas e apontadas como outras formas de fazer comunicação. Assim, o que se coloca como outra lente ou forma de olhar o processo comunicativo é apropriado como técnica e/ou estratégia, reforçando a perspectiva gestionária/instrumental da noção de comunicação organizacional.

Tal movimento evidencia as relações de força nessa construção discursiva e o poder das verdades oriundas dos modelos gestionários - e construídas ao longo de mais de um século - de ainda se sobreporem às concepções que advêm dos campos da comunicação, da filosofia, da psicologia e/ou da sociologia na construção do saber-prática discursiva da comunicação organizacional.

Em outros termos, os construtos apresentados nas Figuras 1 e 2, postulados pelos diferentes grupos de autores em posições subjetivas, ao serem apropriados por outros autores, tendem a ser regrados por funções enunciativas que os vinculam, 
novamente, à noção de comunicação como ferramenta nos processos de gestão organizacional, com ênfase no fazer comunicação no âmbito das organizações. Talvez isso decorra da força do sistema capitalista e do paradigma utilitário que sustenta o modelo de gestão das organizações e, ainda, da forte ligação entre os estudos organizacionais e a comunicação organizacional, fazendo que esta seja assumida e compreendida como ferramenta estratégica de controle e gestão. Percebese, assim, que

tanto no âmbito das práticas como no dos estudos acadêmicos, a comunicação organizacional desenvolveu-se vinculada à noção de informação e, de certa forma, de uma informação utilitária e, consequentemente, os termos comunicação e informação foram - e ainda o são muitas vezes - utilizados como sinônimos. (Mourão, 2019, p.19)

Ainda que a comunicação também se configure como informação e que tenha, de fato, um viés utilitário, ela é mais complexa e, para além da noção bipolarizada emissor/receptor, deve considerar o interlocutor no processo comunicacional (Oliveira, 2010), bem como a complexidade desse processo, o fato de que a comunicação é de natureza relacional e ocorre na disputa de sentidos (Baldissera, 2009).

\section{CONSIDERAÇÕES FINAIS}

A análise arqueológica de discurso que inspirou a elaboração dos procedimentos metodológicos aplicados na pesquisa que subsidiou este artigo mostrou-se singular ao proporcionar a compreensão do encadeamento conceitual da comunicação organizacional. Entre essas singularidades está o fato de a análise não se prender aos enunciados postulados pelos autores/ pesquisadores em posições subjetivas, nem às especificidades de cada um deles, mas à forma como esses construtos são apropriados, por vezes ressignificados, nesse processo de apropriação e reverberados por outros autores pesquisadores, dando a ver as relações saber-poder-verdade na conformação do saber-prática discursiva da comunicação organizacional.

Além de elucidar enunciados discursivos e não discursivos, é fundamental apreender a função enunciativa que rege a conformação dos construtos apropriados como verdade. Nesse movimento, percebemos que as relações e articulações entre os construtos, observando sua vinculação com os enunciados reitores, é que fazem emergir verdades conceituais. Desse modo, mais do que a autoria dos enunciados, o que importa é o efeito de verdade desses e das formações discursivas, sempre resultantes dessas articulações que também denotam as relações saber-poder-verdade.

Pelos achados da pesquisa, podemos dizer que o encadeamento conceitual do saber-prática discursiva da comunicação organizacional apresenta transformações epistêmicas, especialmente em função de vinculações teóricas de posições subjetivas que desenvolvem construtos mais ou menos enraizados aos estudos organizacionais. Todavia, conforme se pode observar a partir dos procedimentos investigativos adotados, as formações discursivas permanecem em relações de força com outras, enraizadas nos modelos gestionários e ainda demonstram, na sua apropriação por outros autores e pesquisadores, a força de funções enunciativas na reverberação dos conceitos e, portanto, na conformação do saber-prática discursiva. De forma geral, essas abordagens colocam em prática um jogo de regras que utiliza conceitos nos quais a estratégia - pensada em relações de eficiência e de eficácia - permanece como função enunciativa na conformação do saber-prática discursiva da comunicação organizacional. 


\section{REFERÊNCIAS}

BALDISSERA, Rudimar. A teoria da complexidade e novas perspectivas para os estudos de comunicação organizacional. In: KUNSCH, Margarida M. Krohling (org.). Comunicação organizacional: histórico, fundamentos e processos. São Paulo: Saraiva, 2009. v.1, p.133-164.

FOUCAULT, Michel. Arqueologia do saber. 8.ed. Rio de Janeiro: Forense Universitária, 2012a.

FOUCAULT, Michel. Ditos e escritos, volume IV: estratégia, poder-saber. 3.ed. Rio de Janeiro: Forense Universitária, 2012b.

FOUCAULT, Michel. Microfísica do poder. 25.ed. Rio de Janeiro: Graal, 2012c.

FOUCAULT, Michel. Resumo dos cursos do Collège de France (1970-1982). Rio de Janeiro: Jorge Zahar Ed., 1997.

GAULEJAC, Vincent de. Gestão como doença social: ideologia, poder gerencialista e fragmentação social. 3.ed. São Paulo: Ideias \& Letras, 2007.

MOURÃO, Isaura Generoso. A construção do saber-prática discursiva da comunicação organizacional. 2019. Tese (Doutorado em Comunicação e Informação) - Faculdade de Biblioteconomia e Comunicação, Universidade Federal do Rio Grande do Sul, Porto Alegre, 2019.

OLIVEIRA, Ivone de Lourdes. Evolução e perspectivas do campo acadêmico da comunicação organizacional e das Relações Públicas. In: CASTRO, Daniel; MARQUES DE MELO, José; CASTRO, Cosette (org.). Panorama da comunicação e das telecomunicações no Brasil. Brasília: Ipea, 2010. p.181-192.

Artigo recebido em 13.05.2021 e aprovado em 09.08.2021. 